\title{
Comparison of Bolus Phenylephrine, Ephedrine and Mephentermine for Maintenance of Arterial Pressure during Spinal Anesthesia in Cesarean Section
}

\author{
Bhattarai B, ${ }^{1}$ Bhat SY, ${ }^{2}$ Upadya $\mathrm{M}^{2}$ \\ 'Department of Anesthesiology, Dhulikhel Hospital, Kathmandu University Hospital, Dhulikhel Kavre, Nepal, ${ }^{2}$ Department of \\ Anesthesiology, Kasturba Medical College, Mangalore, India.
}

\section{ABSTRACT}

Introduction: Hypotension is common following spinal anesthesia. Various vasopressors have been indicated to prevent it. The study compares three such agents namely phenylephrine, ephedrine and mephentermine.

Methods: The study included 90 patients undergoing elective and emergency cesarean section who developed hypotension following subarachnoid blockade. Parturient were randomly divided into three groups each group had 30 patients. Group P received bolus of Phenylephrine 25 microgram, where as group E received Ephedrine $5 \mathrm{mg}$ and Group M received Mephentermine $6 \mathrm{mg}$.

Results: It was found that rise of blood pressure was significantly higher in case of phenylephrine group in first six minutes, after the bolus, there was significant reduction in the heart rate in phenylephrine group, but there was tachycardia following administration of bolus ephedrine and mephenteramine. Neonatal APGAR score were similar in all three groups.

Conclusions: All three drugs maintained hemodynamics within 20 percent of the baseline values on intravenous administration.

Key Words: APGAR, ephedrine, hypotension, mephentermine, phenylephrine, spinal anesthesia

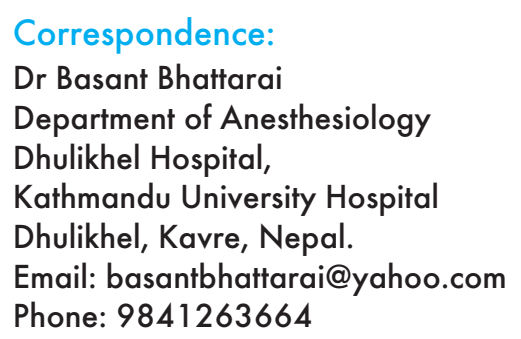




\section{INTRODUCTION}

Hypotension is common following spinal anesthesia with the incidence up to $80 \%$ despite fluid preload and lateral uterine displacement. ${ }^{1}$ During cesarean section done under spinal anesthesia, maternal hypotension is associated with dizziness, nausea, vomiting, and can also cause fetal bradycardia ${ }^{2}$ and acidosis. ${ }^{3}$ Management of hypotension includes administration of fluids, and preemptive administration of vasopressors. In 1965, Gries and Crandell showed rapid infusion of crystalloid helped partially restore uterine blood flow. ${ }^{4}$ But crystalloids have short half life and over infusion can cause dilutional anemia. ${ }^{5}$ Thus the patient may be at greater risk of pulmonary edema. ${ }^{6}$

Several other methods have been tried to prevent hypotension like left uterine displacement ${ }^{7}$, leg compression and elevation ${ }^{8}$, prophylactic administration of phenylephrine and ephedrine ${ }^{9}$, angiotensin $\mathrm{II}^{10}$ and atrial naturetic peptide. $^{11}$

This study evaluates the effects of intravenous phenylephrine 25 micrograms, ephedrine 5 milligram and mephentermine 6 milligram as a vassopressor therapy in case of hypotension associated with spinal anesthesia in patients undergoing cesarean section.

\section{METHODS}

This is a prospective, interventional study conducted among 90 parturients undergoing elective or emergency caesarian sections at Lady Goshen Hospital, Mangalore form May 2007 to May 2008. Only those who consented to the study were included.

Patients with hypertensive disorders of pregnancy, (defined as systolic blood pressure of more than 140 $\mathrm{mm}$ of $\mathrm{Hg}$ and diastolic pressure of more than $100 \mathrm{~mm}$ of $\mathrm{Hg}$ ), polyhydramnios, multiple pregnancies, suspected intrauterine growth retardation, hemoglobin of less than 9 gram per deciliter and the patients with co existing medical diseases were excluded from the study.

After pre anesthetic examination, the elective cases were premedicated with ranitidine $150 \mathrm{mg}$ at night and metoclopramide $10 \mathrm{mg}$ and ranitidine $50 \mathrm{mg}$ intravenous one hour before surgery. Emergency cases were premedicated with intravenous $50 \mathrm{mg}$ of ranitidine and $10 \mathrm{mg}$ of metoclopramide at the time of pre anesthetic examination. Patients were preloaded with Ringer lactate $10 \mathrm{ml} / \mathrm{kg}$ via $18 \mathrm{G}$ cannula.
Patients were shifted to operating suit in left lateral position and oxygen was started with Hudson's mask at rate of 6 liters per minute irrespective of oxygen saturation. Oxygen was continued till the baby was extracted and umbilical cord clamped.

Blood pressure was taken thrice before and after preloading, and the mean values were taken as the baseline. Then with all aseptic precautions $2 \mathrm{ml}$ of $0.5 \%$ hyperbaric bupivacaine was instilled in the sub arachnoid space in $L_{3}-L_{4}$ interspace using $23 G$ spinal needle after confirming free flow of cerebro spinal fluid. The patient was turned supine immediately and wedge was kept under the right flank. This was considered as time zero. Blood pressure measurement was done at time zero. Immediately after, blood pressure of the patient was taken every three minutes for first half an hour then every five minutes till the end of surgery. Injection Oxytocin 20 units in Ringer lactate as slow intravenous infusion was started after cord was clamped.

The patients were randomly grouped into group $P$, group E and group M. Group P received phenylephrine 25 microgram, Group E received ephedrine $5 \mathrm{mg}$ as bolus and Group $\mathrm{M}$ received mephentermine, $6 \mathrm{mg}$ as bolus, if there was hypotension, which was defined as fall in Blood pressure of $20 \%$ of baseline or systolic blood pressure of $>90 \mathrm{mmhg}$. Complications like bradycardia, (defined as heart rate of less than 60) nausea and vomiting were treated accordingly. APGAR score of the child was taken by the pediatrician who was blinded to the vassopressor used.

Block height in each group time, onset of block and time of onset of hypotension and number of boluses required were noted. The results were analyzed statistically using SPSS $V$ 16. Intergroup comparison was done by one way Analysis of Variance (ANOVA). A p value of less than 0.05 was considered to be statistically significant. The study was ethically approved by the hospital ethical board.

\section{RESULTS}

All the three groups were comparable in demographic profiles and baseline parameters. Maternal heart rate, maternal systolic Blood Pressure, maternal diastolic blood pressure, hemoglobin and fetal heart rate was similar in all three groups. Three groups were comparable in subarachnoid block to hypotension time, subarachnoid block to delivery time and APGAR at 1 and 6 minutes (Table 1). 
Table 1. Comparison of demographic profiles in three group of patients

\begin{tabular}{lllll}
\hline Parameters & Group P & Group E & Group M & p-value \\
\hline Age (years) & $25.23 \pm 3.21$ & $24.89 \pm 3.54$ & $24.58 \pm 3.39$ & 0.740 \\
Weight $(\mathrm{kg})$ & $55.40 \pm 5.55$ & $55.20 \pm 5.33$ & $54.83 \pm 6.25$ & 0.999 \\
Height $(\mathrm{cm})$ & $148.16 \pm 4.25$ & $148.75 \pm 4.42$ & $149.09 \pm 3.99$ & 0.993 \\
Parity & $1.60 \pm .72$ & $1.68 \pm 0.71$ & $1.58 \pm 0.764$ & 0.793 \\
Maternal heart rate $(\mathrm{bpm})$ & $89.27 \pm 10.6$ & $89.03 \pm 10.42$ & $90.84 \pm 9.52$ & 0.652 \\
Maternal SBP $(\mathrm{mm} \mathrm{Hg})$ & $116.53 \pm 5.40$ & $116.90 \pm 6.60$ & $114.16 \pm 19.57$ & 0.652 \\
Maternal DBP $(\mathrm{mm} \mathrm{Hg})$ & $76.17 \pm 4.676$ & $76.38 \pm 5.328$ & $75.97 \pm 4.902$ & 0.950 \\
Fetal heart rate $(\mathrm{bpm})$ & $141.73 \pm 4.835$ & $141.41 \pm 5.039$ & $140.03 \pm 6.7$ & 0.456 \\
SAB to hypotension & $3.63 \pm 3.33$ & $4.55 \pm 0.42$ & $4.20 \pm 2.71$ & 0.941 \\
SAB to delivery & $12.06 \pm 4.68$ & $12 \pm 4.55$ & $10.54 \pm 10.87$ & 0.947 \\
APGAR at 1 min & $7.40 \pm 0.814$ & $7.31 \pm 0.806$ & $7.32 \pm 0.791$ & 0.897 \\
APGAR at 6 min & $9.00 \pm 0.000$ & $9.00 \pm 0.000$ & $9.00 \pm 0.000$ & NS \\
\hline
\end{tabular}

There was statistically significant decrease in the blood pressure at the onset of hypotension. There was significant rise in the blood pressure after administration of the drug. On intergroup comparison, systolic blood pressure in phenylephrine group was higher than in other groups. The rise in blood pressure post drug administration was significantly higher in phenylephrine group as compared to mephentermine group (Table 2).

Table 2. Changes in systolic blood pressure

\begin{tabular}{|c|c|c|c|c|c|c|}
\hline \multirow[t]{2}{*}{ Time Interval } & \multicolumn{3}{|c|}{ Systolic Blood Pressure } & \multicolumn{3}{|c|}{ Intergroup Comparison } \\
\hline & Group P & Group E & Group M & P-M & $P-E$ & E-M \\
\hline SBP Pre op & $116.17 \pm 4.67$ & $118.38 \pm 5.32$ & $115.97 \pm 4.90$ & - & - & - \\
\hline $\mathrm{SBP}_{0}$ & $120.00 \pm 8.30$ & $120.69 \pm 7.87$ & $120.00 \pm 7.85$ & - & - & - \\
\hline $\mathrm{SBP}_{3}$ & $104.33 \pm 7.16$ & $102.07 \pm 7.73$ & $101.61 \pm 7.89$ & - & - & - \\
\hline $\mathrm{SBP}_{6}$ & $110.33 \pm 12.17$ & $103.03 \pm 7.36$ & $105.81 \pm 8.47$ & ++ & ++ & - \\
\hline $\mathrm{SBP}_{9}$ & $116.83 \pm 6.36$ & $108.28 \pm 5.86$ & $109.13 \pm 9.49$ & ++ & ++ & - \\
\hline $\mathrm{SBP}_{12}$ & $117.67 \pm 5.83$ & $109.83 \pm 5.08$ & $109.84 \pm 7.12$ & ++ & ++ & - \\
\hline $\mathrm{SBP}_{15}$ & $116.83 \pm 4.82$ & $111.72 \pm 9.28$ & $112.26 \pm 7.51$ & - & - & - \\
\hline $\mathrm{SBP}_{18}$ & $114.17 \pm 6.95$ & $108.62 \pm 8.54$ & $109.84 \pm 9.87$ & ++ & ++ & - \\
\hline $\mathrm{SBP}_{21}$ & $113.33 \pm 6.34$ & $107.76 \pm 7.97$ & $110.81 \pm 7.53$ & - & - & - \\
\hline $\mathrm{SBP}_{24}$ & $115.33 \pm 8.29$ & $110.00 \pm 6.68$ & $110.97 \pm 8.40$ & ++ & ++ & - \\
\hline $\mathrm{SBP}_{27}$ & $112.33 \pm 8.97$ & $109.83 \pm 7.25$ & $111.77 \pm 11.22$ & - & - & - \\
\hline $\mathrm{SBP}_{30}$ & $115.83 \pm 8.31$ & $110.34 \pm 7.55$ & $113.39 \pm 7.89$ & - & - & - \\
\hline
\end{tabular}

Within the Groups $\mathrm{P}<0.001, \mathrm{P}<0.05,{ }^{\circ} \mathrm{P}>0.05$. Between the Groups $+\mathrm{P}<0.001,++\mathrm{P}<0.05,-\mathrm{P}>0.05$. 
There was also significant rise of diastolic blood pressure post administration of the drug but rise was more in phenylephrine group than in ephedrine and mephentermine group. There was no significant difference in the change in the blood pressure in between ephedrine and mephentermine group (Table 3).

Table 3. Changes in diastolic blood pressure

\begin{tabular}{lllllll}
\hline Time Interval & \multicolumn{3}{l}{ Systolic Blood Pressure } & & \multicolumn{3}{l}{ Intergroup Comparison } \\
\hline & Group P & Group E & Group M & P-M & P-E & E-M \\
DBP $_{\text {Pre op }}$ & $76.17 \pm 4.67$ & $76.38 \pm 5.32$ & $75.97 \pm 4.90$ & - & - & - \\
DBP $_{0}$ & $77.17 \pm 5.97$ & $77.24 \pm 5.27$ & $76.61 \pm 5.06$ & - & - & - \\
DBP $_{3}$ & $65.50 \pm 5.30$ & $65.86 \pm 5.01$ & $64.84 \pm 5.08$ & - & - & - \\
DBP 6 & $71.83 \pm 7.13$ & $64.48 \pm 4.29$ & $66.77 \pm 5.56$ & ++ & ++ & - \\
DBP 9 & $77.83 \pm 3.13$ & $71.03 \pm 4.09$ & $76.45 \pm 2.94$ & - & - & - \\
DBP 12 & $78.83 \pm 2.52$ & $73.45 \pm 5.01$ & $77.42 \pm 3.62$ & - & ++ & - \\
DBP 15 & $74.50 \pm 4.22$ & $71.38 \pm 6.53$ & $71.94 \pm 4.774$ & - & - & - \\
DBP 18 & $73.67 \pm 6.00$ & $68.62 \pm 6.25$ & $71.13 \pm 5.58$ & - & - & - \\
DBP 21 & $72.33 \pm 5.04$ & $67.93 \pm 4.33$ & $69.35 \pm 4.23$ & - & - & - \\
DBP 24 & $73.67 \pm 6.42$ & $69.14 \pm 4.02$ & $72.10 \pm 7.50$ & ++ & ++ & ++ \\
DBP 27 & $72.83 \pm 7.62$ & $71.03 \pm 5.06$ & $72.58 \pm 6.56$ & - & - & - \\
DBP 30 & $74.00 \pm 5.15$ & $70.34 \pm 5.49$ & $73.55 \pm 6.35$ & - & - & - \\
\hline
\end{tabular}

Within the Groups $\mathrm{P}<0.001, \mathrm{P}<0.05,{ }^{\circ} \mathrm{P}>0.05$. Between the Groups $+\mathrm{P}<0.001,++$ $P<0.05,-P>0.05$.

Heart rate was raised in all three groups during hypotension, which was significant, but post drug administration there was significant drop in the heart rate in phenylephrine group as compared to Ephedrine and Mephentermine group. Where as in group $\mathrm{E}$ and $\mathrm{M}$ there was rise in heart rate post administration of the drug (Table 4).

Table 4. Changes in heart rate

\begin{tabular}{|c|c|c|c|c|c|c|}
\hline \multirow[t]{2}{*}{ Time Interval } & \multicolumn{2}{|c|}{ Systolic Blood Pressure } & \multirow[b]{2}{*}{ Group M } & \multicolumn{3}{|c|}{ Intergroup Comparison } \\
\hline & Group P & Group E & & P-M & P-E & $\mathrm{E}-\mathrm{M}$ \\
\hline HR Pre op & $83.63 \pm 7.04$ & $86.34 \pm 7.33$ & $86.94 \pm 6.39$ & - & - & - \\
\hline HR 0 & $83.63 \pm 7.03$ & $86.34 \pm 7.33$ & $86.94 \pm 6.39$ & - & - & - \\
\hline HR 3 & $93.83 \pm 4.86$ & $91.66 \pm 6.40$ & $93.61 \pm 4.87$ & - & - & - \\
\hline HR 6 & $81.67 \pm 9.93$ & $93.38 \pm 6.43$ & $91.19 \pm 8.83$ & ++ & ++ & - \\
\hline HR 9 & $82.30 \pm 5.55$ & $91.97 \pm 5.55$ & $90.32 \pm 5.00$ & ++ & ++ & - \\
\hline HR 12 & $84.20 \pm 5.73$ & $93.21 \pm 5.88$ & $95.23 \pm 4.46$ & ++ & ++ & - \\
\hline HR 15 & $84.13 \pm 4.87$ & $90.86 \pm 5.38$ & $90.00 \pm 3.26$ & ++ & ++ & - \\
\hline HR 18 & $85.70 \pm 5.51$ & $90.41 \pm 3.97$ & $90.77 \pm 2.40$ & ++ & ++ & - \\
\hline HR 21 & $85.87 \pm 6.68$ & $90.83 \pm 5.76$ & $90.90 \pm 5.96$ & ++ & ++ & - \\
\hline HR 24 & $85.37 \pm 5.04$ & $91.90 \pm 4.55$ & $91.87 \pm 5.90$ & ++ & ++ & - \\
\hline HR 27 & $87.43 \pm 8.23$ & $92.31 \pm 5.4$ & $94.68 \pm 6.72$ & ++ & ++ & - \\
\hline HR 30 & $83.50 \pm 6.45$ & $91.00 \pm 4.8$ & $89.00 \pm 2.29$ & ++ & ++ & - \\
\hline
\end{tabular}


The number of bolus required in Phenylephrine was significantly higher whereas Ephedrine and mephentermine group required similar number of boluses (Table 5 ).

One patient in group $\mathrm{P}$ complained of nausea and three patients in ephedrine complained of thumping heart. There was no significant difference in APGAR score, all three group had APGAR of more than 7.

Table 5. Number of boluses required in each group

\begin{tabular}{lll}
\hline Group & Mean number of bolus & Standard deviation \\
\hline P & 3.51 & 0.51 \\
E & 2.54 & 0.52 \\
M & 2.87 & 0.37 \\
\hline
\end{tabular}

\section{DISCUSSION}

One of the commonest complications of spinal anesthesia is hypotension. ${ }^{1}$ Undertreated and over treated hypotension occurring during cesarean section delivery can cause undue effects to both mother and fetus. ${ }^{2}$ There have been several attempts to find the optimal therapy for hypotension occurring during cesarean section. Several measures to prevent hypotension include left uterine displacement $^{7}$, application of tight fitting stockings ${ }^{8}$, preloading with colloids and crystalloids ${ }^{12}$ and prophylactic intramuscular administration of vassopressor agents. ${ }^{9,13}$ All these maneuvers have their own limitations. Fluid preloading, although considered to be standard practice, has been shown to be non effective. Tight fitting elastic stockings, although help in some degree, their use is limited by the cost and moreover over they are not stand alone method to prevent hypotension. ${ }^{8}$ Intramuscular administration of vassopressors has been found to cause hypertension and fetal acidosis ${ }^{9}$, so this practice has been abandoned. So the use of vassopressor during the time of hypotension is appropriate, as arterial vasodilatation is the main cause of hypotension. It has been shown that the percentage decrease in placental circulation is related to percentage reduction in maternal arterial pressure but not absolute reduction in pressure. So administration of vasopressor agent whenever it's appropriate is logically correct. Hypotension in most of the studies has been defined as values ranging from 20 to 30 percent reduction from baseline systolic arterial pressure or mean arterial pressure. Incidence of hypotension clearly depends on the definition. For the purpose of our study we defined hypotension as reduction in arterial pressure by $20 \%$ from the baseline systolic pressure.

Phenylephrine is directly acting alpha 1 adrenergic agonist where as Ephedrine and Mephentermine act indirectly on both alpha and beta receptors. Although phenylephrine has only alpha adrenergic activity, earlier it was considered to cause reduction in uterine blood flow, but Naag et al $^{14}$ in his review mentioned that phenylephrine causes less fetal acidosis than ephedrine. Other studies using phenylephrine in pregnant patients have also found that although it causes fetal acidosis, it's less than that caused by ephedrine and is non detrimental to neonatal outcome. . $^{15-20}$

Thomas and colleagues ${ }^{15}$ reported that bolus phenylephrine 100 microgram is as effective as ephedrine $5 \mathrm{mg}$ in restoring maternal blood pressure above $100 \mathrm{~mm}$ of $\mathrm{Hg}$. Moron and colleagues ${ }^{16}$ gave ephedrine $10 \mathrm{mg}$ or phenylephrine 80 microgram bolus to maintain systolic blood pressure above 100. Ramanathan and colleagues ${ }^{17}$ studied 127 healthy patients undergoing cesarean section under epidural anesthesia and they concluded that transient maternal hypotension does not affect the neonatal acid base status.

In our study all the three vasopressor agents maintained Blood pressure within $20 \%$ of baseline values, though phenylephrine maintained better in first six minutes. This can be attributed to the peak onset of phenylephrine within one minute, but this group required more number of bolus, which can be attributed to short duration of action of intravenous bolus (about 10 minutes). Where as in other groups, peak onset was slightly slow which can be attributed to onset of action of ephedrine 2-5 and mephentermine in five minutes.

In our study phenylephrine causes significant reduction in heart rate after the bolus dose, which is a consistent effect in phenylephrine treated women in other studies. In spinal anesthesia, since there is decreased venous return, decreased venous pressure and a decreased right heart pressure thus slowing of the heart rate is expected on the basis of the Bainbridge reflex. Bradycardia is also expected in high spinal, probably due to some paralysis of the cardiac accelerator nerve. We found that the maternal heart rate was slower with phenylephrine than with ephedrine and mephentermine. This can be attributed to selective action on alpha receptors and no action on beta receptors. Studies by Thomas DG et al showed significant bradycardia that warranted treatment. Our study had none as the bolus drug was 25 microgram in our case whereas it was 100 microgram in that study.

\section{CONCLUSIONS}

The study found that all three drugs maintained hemodynamic within 20 percent of the baseline values on intravenous administration. There was no undue effect on the mother and the fetus as assessed by hemodynamic parameter and fetal APGAR scores.

\section{\begin{tabular}{l|l|l|l|l|l|l|} 
JNMA & VIL 49 & Na. 1 & ISSUE & 177 & JAN-MAR, 2010
\end{tabular}}




\section{REFERENCES}

1. Rout CC, Rocke DA. Prevention of Hypotension following spinal anesthesia for cesarean section. International anesthesiology clinics. 1994;117-35.

2. Eloner H, Barchohana J, Bartoshe AK. Influence of Post spinal hypotension on fetal electrogram. Am J Obstet Gynecol. 1960;80:560-72.

3. Corke BC, Datta S, Ostheimer GW, Weiss JB, Alper MH. Spinal anesthesia for Caesarean section. The influence of hypotension on neonatal outcome. Anesthesia. 1982 Jun;37(6):658-62.

4. Greiss FC, Crandell DL. Drug Therapy in hypotension induced by sub arachnoid block during pregnancy; observation on gravid ewes. Journal of American Medical Association. 1965;191:793-6.

5. Carralho JCA, Mathias RS, Senra WG, Torres MLA, Vas Cincelos A, de Moraes JC, et al. Maternal and fetal and neonatal consequences of acute hydration during epidural anesthesia for cesarean section. Regional anesthesia. 1993;18(25):19.

6. Mac lennan FM, Macdonald AF, Campbell DM. Lung water during puerperium. Anesthesia. 1987;42:141-7.

7. Kundra P, Khanna S, Habeebullah S, Ravishankar M. Manual displacement of the uterus during Caesarean section. Anesthesia. 2007 May;62(5):460-5.

8. Rout CC, Rocke DA, Gouuse E. Leg elevation and wrapping in prevention of hypotension following spinal anesthesia for elective caesarian section. Anesthesia. 1993 Apr;48(4):304-8.

9. Ayorinde BT, Buczkowski P, Brown J, Shah J, Buggy J. Evaluation of preemptive intramuscular Phenylephrine and ephedrine for reduction of spinal anesthesia induced hypotension during cesarean section. British Journal of Anesthesia. 2001;86(3):371-6.

10. Ramin SM, Ramin KD, Cox K, Magress RR, Shearer VE, Gant NF. Comparison of prophylactic angiotensin II versus ephedrine infusion for prevention of maternal hypotension during spinal anesthesia. American journal of obstetric and gynecology. 1994;171(3):734-9.
11. Pierce ET, Carr DB, Datta S. Effects of ephedrine and Phenylephrine on maternal and fetal atrial natriuretic peptide levels during elective cesarean section. Acta Anaesthesiol Scand. 1994 Jan;38(1):48-5.

12. Karinen J, Räsänen J, Alahuhta S, Jouppila R, Jouppila P. Effect of crystalloid and colloid preloading on uteroplacental and maternal hemodynamic state during spinal anesthesia for caesarean section. Br J Anaesth. 1995 Nov;75(5):531-5.

13. Kang YG, Abouleish E, Caritis S. Prophylactic intravenous ephedrine infusion during spinal anesthesia for cesarean section. Anesth Analg. 1982 Oct;61(10):839-42.

14. Ngan Kee WD, Khaw KS. Vasopressors in obstetrics: what should we be using? Curr Opin Anaesthesiol. 2006 Jun;19(3):23843.

15. Thomas DG, Robson SC, Redfern N, Hughes D, Boys RJ. Randomized trial of bolus Phenylephrine or ephedrine for maintenance of arterial pressure during spinal anesthesia for Caesarean section. Br J Anaesth. 1996 Jan;76(1):61-5.

16. Moran DH, Perillo M, LaPorta RF, Bader AM, Datta S. Phenylephrine in the prevention of hypotension following spinal anesthesia for cesarean delivery. J Clin Anesth. 1991 JulAug;3(4):301-5,43.

17. Ramanathan S, Grant GJ. Vasopressor therapy for hypotension due to epidural anesthesia for cesarean section Acta Anaesthesiol Scand. 1988 Oct;32(7):559-65

18. Ramathan S, Friedman S, Moss P Arismendy J, Turndorf H. Phenylephrine for the treatment of maternal hypotension due to epidural anesthesia. Anesthesia and Analgesia. 1984;63:262.

19. Alahuhta S, Rasanem J, Joupilla P, Joupilla R, Hollmen AI. Ephedrine and Phenylephrine for avoiding hypotension due to spinal anesthesia for caesarian section. International journal of Obstetric anesthesia. 1992;1:129-34.

20. Hall PA, Bennett A, Wilkes MP, Lewis M. Spinal anesthesia for caesarean section: comparison of infusions of Phenylephrine and ephedrine. Br J Anaesth. 1994 Oct;73(4):471-4. 